\title{
Análise da influência de atributos fisiográficos e morfométricos na definição da suscetibilidade de bacias hidrográficas à ocorrência de corridas de massa \\ Physiographic and morphometric attributes influence analysis in the definition of river basins susceptibility to debris flow occurrence
}

\author{
Rodrigo Irineu Cerri', Fábio Augusto Gomes Vieira Reis², Marcelo Fischer Gramani³, \\ Beatriz Marques Gabelini ${ }^{1}$, José Eduardo Zaine ${ }^{2}$, Felipe Pereira Sisto ${ }^{1}$, Lucilia do Carmo Giordano ${ }^{2}$ \\ ${ }^{1}$ Programa de Pós-Graduação em Geociências e Meio Ambiente, Instituto de Geociências e Ciências Exatas, Universidade \\ Estadual Paulista "Júlio de Mesquita Filho" - UNESP, Avenida 24A, 1.515 - Bela Vista, CEP 13506-900, Rio Claro, SP, Brasil \\ (roocerri@gmail.com; bgabelini@gmail.com; felipe_ps@hotmail.com) \\ 2Departamento de Geologia Aplicada, Instituto de Geociências e Ciências Exatas, Universidade Estadual Paulista "Júlio de \\ Mesquita Filho” - UNESP, Rio Claro, SP, Brasil (fabioreis@rc.unesp.br; jezaine@rc.unesp.br; lcg@ecogeologia.com.br) \\ ${ }^{3}$ Instituto de Pesquisas Tecnológicas (IPT), São Paulo, SP, BR (mgramani@ipt.br)
}

Recebido em 19 de junho de 2017; aceito em 12 de dezembro de 2017

\begin{abstract}
Resumo
A Serra do Mar paulista, nos últimos 50 anos, passou por uma série de eventos pluviométricos intensos, que ocasionaram acidentes diversos relacionados a processos de dinâmica superficial, com consequências sociais, econômicas e ambientais catastróficas, principalmente nos municípios de Cubatão, São Sebastião e Caraguatatuba. Em 1967, ocorreu, entre Caraguatatuba e São Sebastião, um dos eventos mais excepcionais de escorregamentos generalizados associados a corridas já registrados no país. O objetivo do trabalho foi analisar atributos fisiográficos e morfométricos em relação à potencialidade de bacias hidrográficas à ocorrência de corridas de massa, na Serra do Mar do litoral norte do Estado de São Paulo. A área de estudo foi dividida em 13 unidades fisiográficas, abrangendo compartimentos de planícies; escarpas da Serra do Mar e espigões digitados; relevo de morros rebaixados e soerguidos pela Falha Camburu; relevos montanhosos e de morros com diferentes características no Planalto de Juqueriquerê; Planalto de Paraitinga na borda das escarpas da Serra do Mar; e morros, morrotes e colinas isoladas. Os resultados demonstraram que bacias hidrográficas localizadas em porções escarpadas, com alta declividade e forte estruturação das drenagens por fraturas/falhas, com vales encaixados, como a unidade fisiográfica II, apresentam maiores valores para os parâmetros morfométricos, indicando maior potencialidade à ocorrência de corridas. Portanto, a compartimentação fisiográfica e a análise dos parâmetros morfométricos possibilitaram a avaliação integrada de diferentes atributos do meio físico em relação à suscetibilidade de bacias hidrográficas à ocorrência de corridas, demonstrando que o controle estrutural na evolução geomorfológica dessas bacias é um fator fundamental tanto na distribuição de encostas com direções favoráveis à ocorrência de escorregamentos como nos resultados dos parâmetros morfométricos.
\end{abstract}

Palavras-chave: Compartimentação Fisiográfica; Parâmetros Morfométricos; Serra do Mar; Escorregamentos; Corridas de Massa.

\begin{abstract}
Serra do Mar mountain range in state of São Paulo, Brazil, in the last 50 years, suffered a series of intense rainfall events that provoked many accidents related to superficial dynamic processes, with catastrophic social, economic and environmental consequences, especially in the cities of Cubatão, São Sebastião and Caraguatatuba. In 1967, in Caraguatatuba and São Sebastião municipalities regions, one of the most incredible landslides associated to movements already registered in Brazil occurred. In this way, the objective of the present research was to analyze the physiographic and morphometric attributes in relation to the river basins potentiality to the occurrence of mass movements, in the Serra do Mar of the north coast of São Paulo State. The studied area was divided in 13 physiographic units, involving plain compartmentalization; Serra do Mar cliffs and spikes; hills relief recessed by Camburu Fail; hilly terrain and terrain with hill with different characteristics in the Juqueriquerê Plateau; Paraitinga Plateau in the border of Serra do Mar cliffs; and hills and isolated hills. The results showed that river basins located in escarped portions, with high declivity and strong drained structure by fails, with valleys
\end{abstract}


enclosed by mountains, like the physiographic unit II, present higher values to the morphometric parameters, which indicated higher potentiality to occurrence of mass movements. Therefore, the physiographic compartmentalization and the morphometric parameters analysis made possible the integrated evaluation of different physical environment attributes in relation to the susceptibility of river basins to the occurrence of mass movements, suggesting that the structural control of geomorphological evolution of these basins is a fundamental factor in both slope distribution with favorable directions to the slides occurrence and the morphometric parameters results.

Keywords: Physiographic Compartmentation; Morphometric Parameters; Serra do Mar mountain range; Landslides; Debris Flow.

\section{INTRODUÇÃO}

A compartimentação fisiográfica é uma das etapas fundamentais para o mapeamento geotécnico e para estudos relacionados ao planejamento e ordenamento territorial, incluindo a definição de áreas suscetíveis e de riscos associados a processos de dinâmica superficial. É um método fundamentado no uso de técnicas de sensoriamento remoto - incluindo procedimentos de fotoanálise e fotointerpretação — para a definição de zonas homólogas com o agrupamento de elementos do meio físico que possuem características semelhantes (Vedovello e Mattos, 1998; Zaine, 2000, 2011). A análise dos diferentes atributos fisiográficos - entre eles, características geológicas, geomorfológicas e pedológicas — apresenta grande importância no estabelecimento das zonas homólogas.

Dentre os processos de dinâmica superficial, as corridas de massa estão condicionadas essencialmente por fatores externos, como a precipitação de alta intensidade, e fatores internos da bacia hidrográfica, como os parâmetros morfométricos e morfológicos, a textura e a permeabilidade do solo (Wilford et al., 2004; Dias et al., 2016). Nesse contexto, as corridas de massa apresentam condicionantes fortemente associados aos parâmetros morfométricos da bacia hidrográfica, além dos atributos fisiográficos citados, que podem afetar a magnitude e a potencialidade, dentre os quais se pode citar o Índice de circularidade (Ic), o Índice de rugosidade (Ir), a Densidade de drenagem (Dd), a Relação do relevo (Rr) e o Índice de Melton (M) (Christofoletti, 1980; Augusto Filho, 1993; Jakob, 1996; De Scally et al., 2001; Chen e Yu, 2011).

Corridas de massa são caracterizadas como um fenômeno de dinâmica híbrida de movimento rápido, ou seja, regida pela mecânica dos solos e dos fluidos, pela mobilização de quantidades relativamente grandes de materiais e por um extenso raio de alcance, sendo maiores que os escorregamentos (Gramani, 2001). No desenvolvimento das corridas de massa existe uma relação bastante integrada da ocorrência dos escorregamentos como fonte de sedimentos nas encostas laterais das drenagens, muitas vezes entulhando boa parte do leito, fornecendo material na forma de solos, fragmentos de rocha e árvores (Takahashi, 1981; Infanti Jr. e Fornasari Filho, 1998; Gramani, 2001). Assim, regiões com altas suscetibilidades à ocorrência de escorregamentos generalizados associados a encostas de vales declivosos e com grande diferença altimétrica podem estar intimamente ligadas às maiores ocorrências de corridas de massa primárias, pois o volume de material transportado pode ser acrescido por materiais advindos dos escorregamentos das encostas.

A Serra do Mar paulista, nesse contexto, apresenta condições favoráveis ao desenvolvimento tanto de escorregamentos generalizados como de corridas de massa, sendo caracterizada por um clima tropical com altos índices pluviométricos em eventos concentrados de precipitação intensa, escarpas e desníveis elevados, com a intensa urbanização das regiões costeiras do país. Dessa forma, bacias hidrográficas localizadas na Serra do Mar podem gerar corridas de massa de diferentes formas:

1. ligadas com grande número de escorregamentos nas encostas, gerando corridas de alta magnitude, mobilizando ou não os sedimentos depositados nos canais de drenagem;

2. sem a presença de escorregamentos, gerando corridas de alta magnitude a partir da mobilização dos materiais depositados nos canais de drenagem (Takahashi, 1981; Iverson et al., 1997; Gramani, 2001, 2013; Dias et al., 2016).

Exemplo desses eventos foi o ocorrido no município de Caraguatatuba no ano de 1967, quando houve intensa precipitação no mês de março concentrada em 3 dias (586 mm), gerando um grande número de escorregamentos generalizados nas encostas dos morros e escarpas que desenvolveram corridas de massa nas principais drenagens da região, ocasionando danos sociais, econômicos e ambientais vultosos, com um grande número de perdas de vidas humanas (Cruz, 1975a; IPT, 1987, 1988, 1991; Cerri e Almeida, 1990; Nakazawa e Cerri, 1990; Ogura e Augusto Filho, 1991; Gramani, 2001).

Associado aos condicionantes fisiográficos, morfométricos e climáticos favoráveis à ocorrência de movimentos de massa, o litoral paulista demonstra uma intensa urbanização, favorecida pelo turismo de temporada. Grandes empreendimentos de importância regional e nacional, como o sistema de rede de duto e gasodutos, unidades de armazenamento e transformação de derivados de petróleo e gás, portos marítimos e rodovias interestaduais, possibilitam a ocorrência de eventos com grande potencial catastrófico.

As bacias hidrográficas selecionadas para o desenvolvimento do presente estudo - Rio Camburu, Rio Santo Antônio, Córrego Canivetal e dos Ribeirões da Divisa, do Pau D'alho e da Aldeia - foram intensamente afetadas pelo evento de 1967 (e.g., Cruz, 1975a, 1975b; Fúlfaro et al., 1976; Gomes et al., 2008; Gramani, 2001; Gomes et al., 2015; IPT, 2006). 
Apresentam grande relevância para o litoral sudeste do país, uma vez que são cortadas pelas rodovias dos Tamoios e RioSantos, que dão acesso ao Porto de São Sebastião, principal local de escoamento de derivados de petróleo do país, e às principais cidades do Sudeste brasileiro, como Rio de Janeiro, Santos e São Paulo. Ressalta-se também a presença de extensa rede de dutovias que transportam óleo e gás das regiões produtoras do pré-sal para as refinarias brasileiras e áreas urbanizadas nas áreas planas logo abaixo das encostas.

Portanto, o objetivo deste trabalho foi analisar atributos fisiográficos e morfométricos em relação à potencialidade de ocorrência de corridas de massa em bacias hidrográficas na Serra do Mar, nos municípios de Caraguatatuba e São Sebastião, São Paulo, por meio da definição de unidades de compartimentação fisiográfica e da análise de parâmetros morfométricos de bacias afetadas pelos eventos de 1967. Este estudo ajudará na compreensão de bacias hidrográficas que apresentam maiores suscetibilidades à ocorrência de corridas de massa, bem como quais fatores fisiográficos podem controlar sua ocorrência.

\section{CARACTERIZAÇÃO DA ÁREA DE ESTUDO}

A área de estudo (Figura 1) se localiza no litoral norte do Estado de São Paulo, nos municípios de Caraguatatuba e São Sebastião. Caraguatatuba apresenta aproximadamente 115 mil habitantes, com área total de cerca de $485 \mathrm{~km}^{2}$, enquanto São Sebastião tem uma população de aproximadamente 83 mil habitantes, em uma área total de 399 km² (IBGE, 2016).

\section{Contexto físico}

Os municípios de Caraguatatuba e São Sebastião, geologicamente, estão inseridos no Sistema Orogênico Mantiqueira ou Província Mantiqueira, caracterizado por uma evolução neoproterozoica, conhecida como Ciclo Brasiliano (Heilbron

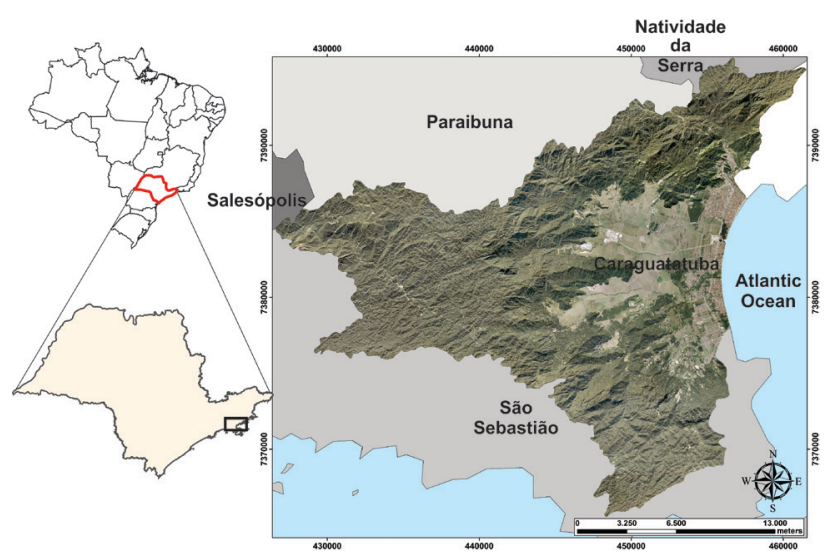

Figura 1. Localização da área de estudo. et al., 2004). Dentro da Província Mantiqueira, esses municípios inserem-se na Faixa Ribeira - ou Cinturão Orogênico Ribeira -, ocupando o Domínio ou Complexo Costeiro, apresentando predominância de gnaisses peraluminosos ricos em granada e sillimanita, com intercalações de espessuras métricas a decamétricas de quartzitos, além da presença de biotita gnaisses bandados, rochas calciossilicátadas e anfibolitos (Heilbron et al., 2004; Hasui et al., 2012). A área de estudo apresenta rochas do embasamento cristalino de idade proterozoica, representadas por gnaisses bandados, rochas granitognaissicas migmatíticas, ortognaisses e paragnaisses do Complexo Costeiro, e por granitos foliados e rochas cataclásticas associadas a zonas de cisalhamento de direção NE, podendo estar cortadas pelos enxames de diques do Jurássico Superior e Cretáceo Inferior (IPT, 1978; Chieregati et al., 1982; Campanha et al., 1994; Hasui et al., 2012). De modo geral, essas rochas ocorrem sempre associadas com forte presença de micas (biotita e muscovita), com foliação/xistosidade bem marcada de direção NE-SW e com valores de mergulho de, no máximo, $35^{\circ}$ (Campanha et al., 1994).

Detalhando a estruturação geral da região, que compreende o município de Caraguatatuba, observa-se forte orientação NE-SW, que corresponde à presença de diversos sistemas de falhas e zonas de cisalhamento de mesma direção, que seguem o trend estrutural desta faixa. Segundo os dados de IPT (1978), Chieregati et al. (1982) e DNPM/ CPRM (1991), a região de Caraguatatuba apresenta as Falhas de Bertioga-Caraguatatuba, dos Quinhentos Réis, do Bairro Alto e de Freire-São Lourenço, além de outras estruturas, como falhas e diques com essa mesma direção.

Geomorfologicamente, a área de estudo apresenta uma complexa compartimentação de relevo, uma vez que está associada à presença das escarpas da Serra do Mar, morros isolados e pequenos maciços nas áreas próximas à orla, além da presença da planície costeira (Silva, 2013). A Serra do Mar é um sistema de escarpamentos e montanhas com $1.500 \mathrm{~km}$ de extensão, entre os Estados de Santa Catarina e Rio de Janeiro, com orientação geral ENE concordando com a estruturação do Cinturão Atlântico. Em sua extensão, a Serra do Mar apresenta grande variedade de características geomorfológicas: alguns trechos são declivosos e contínuos, outros são irregulares e heterogêneos. Além de apresentar limites descontínuos e irregulares, as regiões declivosas da Serra do Mar, por vezes, chegam próximo à linha de costa e outras avançam em direção ao Planalto Atlântico. Essa variação pode ser explicada pela presença de arranjos de falhas e transcorrências complexas e eventos morfotectônicos ligados à gênese do Planalto Attântico durante o Pleistoceno e Mioceno (Vieira e Gramani, 2015). A Serra do Mar no Estado de São Paulo é caracterizada como um típico compartimento de borda de planalto, frequentemente nivelado no topo, em altitudes que variam de 800 a $1.200 \mathrm{~m}$, podendo ser dividida em dois segmentos principais: 
1. Segmento Sul, com extensão de Santos até o Vale do Rio Ribeira do Iguape;

2. Segmento Norte, que ocorre entre a Ilha de São Sebastião e o Estado do Rio de Janeiro, no qual se insere a área de estudo do presente trabalho (Vieira e Gramani, 2015).

As principais características geomorfológicas que podem ser destacadas para a área de estudo e observadas em análises de fotografias aéreas são (Ponçano, 1981; Ross e Moroz, 1997):

1. presença bem marcada de dissecação da paisagem;

2. vales profundos e encaixados (normalmente em estruturas geológicas, como zonas de falha e zonas de fratura);

3. alta densidade de drenagens;

4. encostas íngremes com topos normalmente angulosos;

5. padrão de drenagem essencialmente influenciado pelas direções de estruturas geológicas (falhas, fraturas e contatos litológicos);

6. as escarpas da Serra do Mar, em diversos pontos, seguem a estruturação geológica da faixa em que estão presentes, com direção preferencial NE-SW.

\section{METODOLOGIA}

\section{Levantamento bibliográfico e vetorização de bases cartográficas}

O levantamento bibliográfico e a fundamentação teórica tiveram como base livros, teses, dissertações e artigos referentes à compartimentação fisiográfica, aos aspectos geológicos, geomorfológicos e de dinâmica superficial (escorregamentos e corridas de massa), bem como aos parâmetros e índices morfométricos que visam à quantificação de aspectos físicos na tentativa de mensurar áreas com maior ou menor potencialidade de ocorrência de movimentos de massa.

Foram utilizadas as cartas topográficas dos municípios de Caraguatatuba e São Sebastião, litoral norte do Estado de São Paulo, folhas Pico do Papagaio (SF-23-Y-D-V-2, 1974), Caraguatatuba (SF-23-Y-D-VI-1, 1974) e São Sebastião (SF-23-Y-VI-3, 1975), na escala 1:50.000 e com equidistância de $20 \mathrm{~m}$ entre as curvas de nível, elaboradas pelo Instituto Brasileiro de Geografia e Estatística (IBGE). Essas cartas foram georreferenciadas e vetorizadas por meio do software ArcGIS 10.1, formando uma base topográfica e um banco de dados digitais, dando suporte para a elaboração dos mapas finais. O datum utilizado foi o SIRGAS2000, fuso $23 \mathrm{~K}$, para todos os materiais cartográficos.

\section{Compartimentação fisiográfica}

Para a realização da compartimentação fisiográfica, foram utilizados pares de fotos aéreas (fotos da Empresa Paulista de Planejamento Metropolitano - EMPLASA do ano de
2011) com o auxílio de estereoscópio. Dessa maneira, com a visualização da área de estudo em $3 \mathrm{D}$, aplicando a metodologia utilizada por Zaine (2011), foi possível sistematizar a metodologia de fotointerpretação. A compartimentação fisiográfica foi realizada na escala 1:50.000, a partir de fotos aéreas com pares estereoscópicos na escala 1:20.000, com o intuito de identificar feições com maior detalhamento.

Essa metodologia se baseia na análise integrada entre elementos do relevo, como geologia, geomorfologia, hidrografia e uso e cobertura da terra, dando suporte na divisão e na delimitação de áreas e regiões com características fisiográficas semelhantes (unidades fisiográficas). Esse método analisa os elementos texturais de relevo e drenagem, amplitude local, declividade média, forma das encostas, topo e fundo de vale, orientação e simetria para buscar a delimitação das unidades fisiográficas do terreno estudado (Figura 2).

Dessa forma, essa metodologia avalia o terreno comparando os atributos interpretados a partir das fotografias ou imagens aéreas, agrupando compartimentos e/ou regiões com características semelhantes (densidade de elementos de drenagem e de relevo, amplitude local, declividade, forma de encosta e vertente, forma do vale e forma do topo).

\section{Parâmetros morfométricos}

Os parâmetros morfométricos buscam caracterizar bacias hidrográficas quanto suas características morfométricas, sendo utilizada para caracterização da suscetibilidade a ocorrência de corridas de massa. Cada parâmetro morfométrico se relaciona com aspectos do meio físico que, de alguma forma, estão diretamente correlacionados com os processos de corridas de massa. Os parâmetros morfométricos utilizados foram:

1. Ic (Augusto Filho, 1993);

2. Ir (Jakob, 1996; De Scally et al., 2001);

3. Dd (Horton, 1945; Jakob, 1996);

4. Rr (Schumm, 1956; Jakob, 1996; Chen e Yu, 2011);

5. M (Melton, 1954).

O Quadro 1 mostra a descrição de cada parâmetro morfométrico utilizado para analisar as bacias hidrográficas e sua potencialidade/suscetibilidade à ocorrência de corridas de massa.

\section{Análise da suscetibilidade/potencialidade à ocorrência de corridas de massa}

Cada bacia hidrográfica dentro das unidades fisiográficas mapeadas foi analisada segundo os critérios de Zaine (2011) e integrada com os parâmetros morfométricos. Assim, cada bacia hidrográfica foi analisada utilizando atributos mapeados durante a compartimentação fisiográfica e somada com os valores dos parâmetros morfométricos observados. 


\begin{tabular}{|c|c|c|c|c|}
\hline \multicolumn{2}{|c|}{ 1. Análise da densidade textural } & \multicolumn{3}{|c|}{ Classes } \\
\hline $\begin{array}{l}\text { Elementos de } \\
\text { análise }\end{array}$ & \multicolumn{4}{|l|}{ Elementos de drenagem e relevo } \\
\hline \multirow{3}{*}{$\begin{array}{l}\text { Critérios de } \\
\text { análise }\end{array}$} & $\begin{array}{l}\text { Densidade dos elementos de } \\
\text { drenagem }\end{array}$ & Baixa (0 a $\left.5 / 10 \mathrm{~km}^{2}\right)$ & Média (5 a 30/10 $\left.\mathrm{km}^{2}\right)$ & Alta $\left(>30 / 10 \mathrm{~km}^{2}\right)$ \\
\hline & & & & \\
\hline & $\begin{array}{l}\text { Densidade dos elementos do } \\
\text { relevo (dissecação e rugosidade } \\
\text { do terreno) }\end{array}$ & 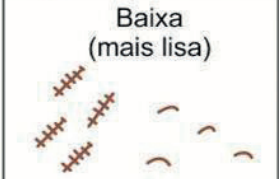 & 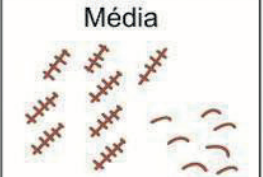 & 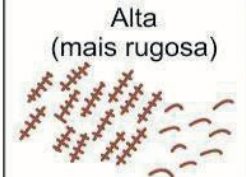 \\
\hline $\begin{array}{l}\text { Propriedade a ser } \\
\text { interpretada }\end{array}$ & Permeabilidade (intergranular) & $\begin{array}{c}\text { Alta } \\
\text { (permeável) }\end{array}$ & Média & $\begin{array}{c}\text { Baixa } \\
\text { (pouco permeável a } \\
\text { mpermeavef) }\end{array}$ \\
\hline \multirow{2}{*}{$\begin{array}{c}\text { Aplicaçōes } \\
\text { Informações interpre- } \\
\text { tadas por esta análise }\end{array}$} & Relação escoamento superficial/infiltração & Baixa & Média & Alta \\
\hline & Espessura e caracteristicas do manto de alteração & $\begin{array}{c}\text { Grande } \\
\text { (espesso; }>5 \mathrm{~m} \text { ) }\end{array}$ & Média & $\begin{array}{c}\text { Pequena } \\
\text { (raso/rocha aflorante) }\end{array}$ \\
\hline \multicolumn{2}{|c|}{$\begin{array}{l}\text { 2. Análise das formas e características do } \\
\text { relevo }\end{array}$} & \multicolumn{3}{|c|}{ Classes } \\
\hline $\begin{array}{l}\text { Elementos de } \\
\text { análise }\end{array}$ & \multicolumn{4}{|c|}{ Declives, vertentes, topos, vales, rupturas de declive (quebras de relevo), cristas e escarpas } \\
\hline \multirow{6}{*}{$\begin{array}{l}\text { Critérios de } \\
\text { análise }\end{array}$} & $\begin{array}{l}\text { a) Amplitude local (variações de } \\
\text { cotas na unidade) }\end{array}$ & $\begin{array}{l}\text { Pequena }(0 \text { a } 100 \mathrm{~m}) \\
-\end{array}$ & $\begin{array}{l}\text { Média }(100 \text { a } 300 \mathrm{~m}) \\
-\end{array}$ & Grande $(>300 \mathrm{~m})$ \\
\hline & b) Declividade & Baixa $(0-15 \%)$ & $\begin{array}{l}\text { Média }(15-30 \%) \\
\end{array}$ & Alta $(>30 \%)$ \\
\hline & $\begin{array}{l}\text { c) Forma de encosta/vertente } \\
\text { (*representação em planta) }\end{array}$ & & & \\
\hline & $\begin{array}{l}\text { d) Forma do vale } \\
\text { (*representação em planta) }\end{array}$ & & & \\
\hline & e) Forma do topo & Aplainadas & Arredondadas & \\
\hline & f) Feições particulares de relevo & \begin{tabular}{|l} 
Identificar e descrever. A \\
* $^{*}$ Consultar quadros Howard (196
\end{tabular} & $\begin{array}{l}\text { ssociar modelos geolóai } \\
\text { 57); Soares e Fiori (1976); Nune }\end{array}$ & $\begin{array}{l}\text { icos já conhecidos. } \\
\text { les et al. (1995). }\end{array}$ \\
\hline \multirow{2}{*}{$\begin{array}{l}\text { Propriedades a } \\
\text { serem } \\
\text { interpretadas }\end{array}$} & Solubilidade & Não solúvel & & Solúvel \\
\hline & Resistência à erosão natural (dureza) & $\begin{array}{c}\text { Baixa } \\
\text { (pouco resistente) }\end{array}$ & $\begin{array}{c}\text { Média } \\
\text { (resistência média) }\end{array}$ & $\begin{array}{c}\text { Alta } \\
\text { (muito resistente) }\end{array}$ \\
\hline \multirow{5}{*}{\begin{tabular}{|l|}
\multicolumn{1}{|c|}{ Aplicações } \\
Informações \\
interpretadas \\
por esta análise \\
Registros de \\
processos geológicos \\
\end{tabular}} & Profundidade do topo rochoso & Profunda & Intermediária & Rasa a subaflorante \\
\hline & Espessura de materiais inconsolidados & Espessa & Intermediária & Delgada a inexistente \\
\hline & Grau de escavabilidade & Pouco resistente & Resistência média & Muito resistente \\
\hline & Potencial à erosão linear (induzida) & Médio a alto & Médio a alto & Médio a baixo \\
\hline & $\begin{array}{l}\text { Potencial a movimentos gravitacionais } \\
\text { de massa }\end{array}$ & Baixo & Médio a alto & Alto \\
\hline
\end{tabular}

Fonte: Zaine (2011).

Figura 2. Critérios utilizados para análise e fotointerpretação como subsídio para a compartimentação fisiográfica. 


\section{RESULTADOS}

\section{Mapa de compartimentação fisiográfica (unidades fisiográficas)}

O mapa de compartimentação fisiográfica, na escala 1:50.000, abrange uma área que vai de São Sebastião a Caraguatatuba, entre as bacias hidrográficas dos Rios Juqueriquerê e Santo
Antônio. Foram obtidas 13 unidades fisiográficas delimitadas a partir de semelhanças e diferenças das características fisiográficas (Figura 3). No mapa estão plotadas as estruturas geológicas com base nos mapas geológicos de Chieregati et al. (1982) e DNPM/CPRM (1991) —, com direção preferencial NE-SW, que estruturam as drenagens e os vales da região de estudo.

As unidades fisiográficas interpretadas e delimitadas foram:

Quadro 1. Descrição e identificação dos parâmetros morfométricos utilizados na classificação das bacias hidrográficas quanto sua potencialidade/suscetibilidade à ocorrência de corridas de massa.

\begin{tabular}{|c|c|c|c|c|}
\hline $\begin{array}{l}\text { Parâmetro } \\
\text { morfométrico }\end{array}$ & Fórmula & Unidade & Descrição & Observação \\
\hline $\begin{array}{l}\text { Índice de } \\
\text { circularidade (Ic) }\end{array}$ & $\mathrm{Ic}=\mathrm{A} / \mathrm{Ac}$ & $\mathrm{km}^{2} / \mathrm{km}^{2}$ & $\begin{array}{c}\text { A: área de bacia } \\
\text { Ac: área do círculo } \\
\text { correspondente ao } \\
\text { mesmo perímetro } \\
\text { da bacia }\end{array}$ & $\begin{array}{c}\text { Índice é capaz de caracterizar as } \\
\text { bacias hidrográficas como mais alongadas } \\
(\mathrm{Ic}<0,5) \text { e mais arredondadas }(\mathrm{lc}>0,5) \text {. }\end{array}$ \\
\hline $\begin{array}{l}\text { Índice de } \\
\text { rugosidade (Ir) }\end{array}$ & $\mathrm{Ir}=\mathrm{H} \times \mathrm{Dd}$ & Adimensional & $\begin{array}{c}\text { H: amplitude } \\
\text { altimétrica } \\
\text { Dd: Densidade de } \\
\text { drenagem }\end{array}$ & $\begin{array}{c}\text { Índice proporcional ao parâmetro Dd (Christofoletti, } \\
\text { 1980). Bacias mais rugosas tendem a ter uma } \\
\text { maior taxa de produção de sedimentos e, } \\
\text { consequentemente, maior disponibilidade de } \\
\text { sedimentos para transporte durante eventos } \\
\text { de corridas de massa. Dessa forma, bacias } \\
\text { hidrográficas com maiores valores de Ir apresentam } \\
\text { maiores valores de Dd. }\end{array}$ \\
\hline $\begin{array}{l}\text { Densidade de } \\
\text { drenagem (Dd) }\end{array}$ & $\mathrm{Dd}=\mathrm{Lt} / \mathrm{A}$ & $\mathrm{km} / \mathrm{km}^{2}$ & $\begin{array}{l}\text { Lt: comprimento } \\
\text { dos canais } \\
\text { A: área da bacia }\end{array}$ & $\begin{array}{l}\text { Quanto maior o índice Dd menor é a capacidade } \\
\text { de infiltração de água dentro da bacia hidrográfica. } \\
\text { Assim, quanto maior a Dd mais rapidamente a } \\
\text { água chega às drenagens, intensificando cheias e, } \\
\text { consequentemente, contribuindo com o aumento da } \\
\text { potencialidade e intensidade de eventos de corrida } \\
\text { de massa. Pode corresponder à disponibilidade de } \\
\text { energia dentro da bacia para ocorrência de corridas } \\
\text { e transportes sedimentares, se correlacionando } \\
\text { com o início dos processos de corrida e com a } \\
\text { disponibilidade de sedimentos para transporte. }\end{array}$ \\
\hline $\begin{array}{l}\text { Relação do } \\
\text { relevo (Rr) }\end{array}$ & $\mathrm{Rr}=\mathrm{Hm} / \mathrm{Lh}$ & $\mathrm{m} / \mathrm{km}$ & $\begin{array}{c}\text { Hm: amplitude } \\
\text { altimétrica } \\
\text { Lh: comprimento da } \\
\text { bacia hidrográfica }\end{array}$ & $\begin{array}{l}\text { Esse índice indica o nível/grau de transporte de } \\
\text { sedimentos que a bacia hidrográfica apresenta, } \\
\text { expressando o potencial de transporte ou } \\
\text { armazenamento de sedimentos dentro da } \\
\text { bacia. Quanto maior a Rr maior será a distância } \\
\text { percorrida pela corrida, ganhando maior } \\
\text { velocidade de fluxo. Isso se deve à indução } \\
\text { desses fenômenos pela gravidade, somada ao } \\
\text { gradiente altimétrico da drenagem. }\end{array}$ \\
\hline $\begin{array}{l}\text { Índice de } \\
\text { Melton (M) }\end{array}$ & $\mathrm{M}=\mathrm{Hm} / \sqrt{ } \mathrm{A}$ & Adimensional & $\begin{array}{l}\text { Hm: amplitude } \\
\text { altimétrica } \\
\text { A: área da bacia }\end{array}$ & $\begin{array}{l}\text { Esse parâmetro morfométrico tem por finalidade } \\
\text { definir áreas suscetíveis a processos de } \\
\text { corridas de massa, incluindo fluxos em geral } \\
\text { (enxurradas, corridas de lama, terra ou detritos). } \\
\text { Assim, quando esse índice apresenta valores } \\
\text { menores que } 0,3 \text {, diz-se que a suscetibilidade a } \\
\text { esses eventos é baixa. Quando } 0,3<\mathrm{M}<0,6 \text {, } \\
\text { a suscetibilidade é média; e quando a bacia } \\
\text { apresenta } \mathrm{M}>0,6 \text {, a suscetibilidade é alta. }\end{array}$ \\
\hline
\end{tabular}


1. Ia, Ib, Ic - Planícies: áreas sedimentares quaternárias na Planície Litorânea, predominantemente plana, com baixa densidade de drenagem. São subdivididas em Ia (planície litorânea em sedimentos fluviomarinhos), Ib (planície litorânea em sedimentos marinhos) e Ic (corpos de tálus e colúvios);

2. II - Escarpas da Serra do Mar e espigões digitados com alta estruturação do relevo por lineamentos estruturais: apresentam alta densidade textural, alta amplitude local com declividades médias a altas (predominante) e vales fechados encaixados em estruturas geológicas (zonas de fraturas e falhas), o que deixa as drenagens com estruturação retilínea. Os topos são frequentemente angulosos, com encostas predominantemente retilíneas e secundariamente côncavas. Apresentam escarpas com afloramento de rocha e anfiteatros de nascentes, principalmente em sub-bacias hidrográficas controladas por estruturas geológicas. A permeabilidade é média e a espessura do manto de alteração varia de baixa a média;

3. Nas bacias hidrográficas dessa unidade se desenvolveram as maiores corridas de massa do ano de 1967, destacando-se as bacias do Rio Santo Antônio, Córrego Canivetal, Aldeia e Divisa e o Ribeirão do Pau D'alho. Frequentemente são encontrados depósitos desses eventos nessas bacias, evidenciando a ocorrência desses processos;

4. III - Relevo de morros rebaixados pela Falha Camburu: apresenta média densidade textural, média amplitude

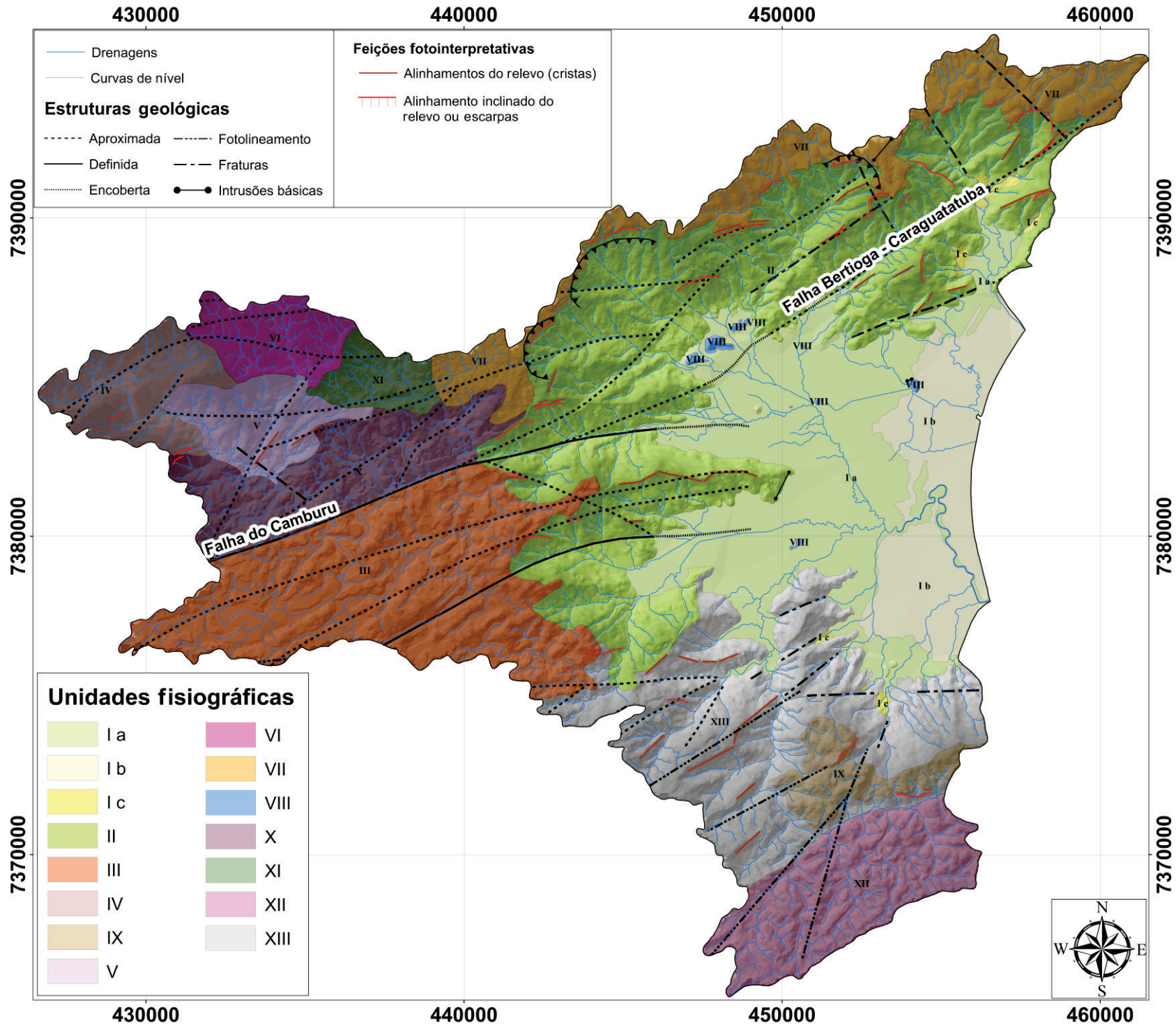

Figura 3. Mapa de unidades fisiográficas da área de estudo, elaborado na escala 1:50.000. 
local, com a presença de vales fechados a abertos, por vezes estruturados por lineamentos estruturais, apresentando média declividade. As encostas dessa unidade são côncavas e retilíneas, com permeabilidade e espessura do manto de alteração média. É caracterizado por um relevo de morros paralelos, com topos localmente angulosos e predominantemente arredondados;

5. IV - Relevo montanhoso com topos rochosos: baixa a média densidade de drenagens, amplitude local média, com declividades que variam de média a alta influenciadas pelos afloramentos rochosos no topo de algumas montanhas. Apresentam vales fechados com topos angulosos - quando associados aos afloramentos rochosos - a levemente arredondados. A espessura do manto de alteração é baixa/média, com média permeabilidade. É caracterizado por um relevo montanhoso no Planalto de Juqueriquerê, com vales profundos com topos rochosos angulosos, com encostas predominantemente retilíneas;

6. V-Relevo montanhoso, norte do Planalto de Juqueriquerê: localiza-se ao norte da unidade fisiográfica IV, com características semelhantes, sem apresentar, porém, relevo com afloramentos rochosos nos topos. Apresenta alta amplitude altimétrica, média a baixa densidade textural, declividade média com topos predominantemente arredondados e secundariamente angulosos sem a presença de topos rochosos. As cristas e as drenagens dessa unidade apresentam leve orientação, que concorda com a orientação observada para as estruturas geológicas (NE-SW). Apresenta média/alta permeabilidade, com espessura do manto de alteração variando entre média e alta;

7. VI - Relevo montanhoso, Planalto de Juqueriquerê, com alinhamento nitido de drenagem NE-SW: localizado ao oeste da unidade fisiográfica IV, caracteriza-se pela ausência de topos com afloramentos rochosos. Geomorfologicamente é caracterizado por um relevo montanhoso, com vales profundos, fechados e com direção preferencial NE-SW. Apresenta topos angulosos e levemente arredondados, baixa/média densidade textural, média amplitude local, com encostas predominantemente retilíneas. A permeabilidade dessa unidade é baixa/média e com espessura do manto de alteração média;

8. VII - Planalto de Paraitinga, borda das escarpas da Serra do Mar: no contexto geomorfológico, está inserido no Planalto de Paraitinga, que corresponde ao rebordo das escarpas da Serra do Mar, na subzona da Morraria do Paraibuna, caracterizada por morrotes baixos de relevo ondulado. Apresenta baixa/média densidade textural, com média amplitude altimétrica e declividades que variam de média a alta. Apresenta topos arredondados e vales relativamente fechados, sem forte estruturação por meio de lineamentos estruturais. As encostas apresentam perfis predominantemente côncavos, com alta permeabilidade e grande espessura do manto de alteração;

9. VIII - Morros, morrotes e colinas isoladas: se encontram isolados na planície litorânea, com baixas amplitudes altimétricas e baixas declividades. Suas encostas são convexas, com manto de alteração de grande espessura;

10. IX-Relevo de morros acima das escarpas: se encontram acima das escarpas e das altas declividades na unidade fisiográfica XIII, dentro do contexto do Planalto de Juqueriquerê. Apresenta baixa densidade textural, média amplitude altimétrica e declividade que varia de baixa a média. É caracterizado por um relevo de morros dentro do Planalto de Juqueriquerê e logo acima das escarpas e dos espigões digitados, com vales fechados e topos localmente angulosos e predominantemente arredondados, com encostas côncavas a retilíneas. Em algumas porções restritas dessa unidade, com mesma direção dos lineamentos estruturais, pode-se observar alguns morros com escarpas curtas e de alta declividade;

11. X-Relevo de morros soerguidos pela Falha Camburu: essa unidade é caracterizada geomorfologicamente pelo relevo de morros inseridos dentro do Planalto de Juqueriquerê. Está localizado ao norte da unidade fisiográfica III e, consequentemente, ao norte da Falha do Camburu. Segundo Campanha et al. (1994), a Falha do Camburu foi responsável pela mudança da amplitude altimétrica dentro do Planalto de Juqueriquerê, gerando um desnivelamento dentro desse planalto, que foi marcado pelas unidades fisiográficas III e X. A unidade fisiográfica $X$ apresenta baixa/média densidade textural, média/alta amplitude altimétrica (superior ao observado para a unidade fisiográfica III), com declividades médias. Apresenta vales fechados, topos localmente angulosos e arredondados, com encostas côncavas a retilíneas;

12. XI - Relevo montanhoso, Planalto de Juqueriquerê, com alinhamento de drenagem WNW-ESE: também inserido no contexto do relevo de morros do Planalto de Juqueriquerê, apresenta baixa densidade textural, média amplitude altimétrica, com declividades que variam de baixa a média. Está localizado ao leste da unidade fisiográfica VI, com nítida mudança na direção das drenagens, que vão de quase N-S na unidade fisiográfica VI para WNW-ESE até E-W na unidade fisiográfica XI. Os vales apresentam-se fechados, com predomínio de drenagens retilíneas, topos predominantemente arredondados, com encostas côncavas a retilíneas;

13. XII-Relevo de morros do Planalto de Juqueriquerê: localiza-se ao sul da área de estudo, insere-se dentro do Planalto de Juqueriquerê e é separado da unidade fisiográfica IX por uma drenagem retilínea com encostas de alta declividade, apresentando maior densidade 
textural (alta). Apresenta amplitude altimétrica média, com declividades variando de baixa a média, com drenagens com vales fechados, com topos aplainados a levemente angulosos, com predomínio de encostas côncavas e retilíneas;

14. XIII - Escarpas e pequenos espigões digitados, com baixa estruturação do relevo por lineamentos estruturais: diferentemente da unidade fisiográfica II, essa unidade apresenta menor estruturação do relevo por meio de lineamentos estruturais, apesar de também ser caracterizada por escarpas e espigões digitados. A densidade textural dessa unidade é média, com alta amplitude altimétrica e declividades que variam de média a baixa. Os vales são fechados, drenagens apresentam-se retilíneas e possuem topos arredondados a angulosos, com encostas predominantemente côncavas e secundariamente retilíneas. Está inserida dentro do contexto geomorfológico da Serrania Costeira, Subzona da Serra do Mar, com escarpas e espigões digitados lineares subparalelos.

\section{Bacias hidrográficas e parâmetros morfométricos}

As bacias hidrográficas selecionadas para a aplicação dos parâmetros morfométricos foram: Rios Camburu e Santo Antônio, Córrego Canivetal e Ribeirões da Divisa, do Pau D'alho e da Aldeia (Figura 4). Essas bacias estão inseridas nas unidades fisiográficas mapeadas, em especial II, III, IV,

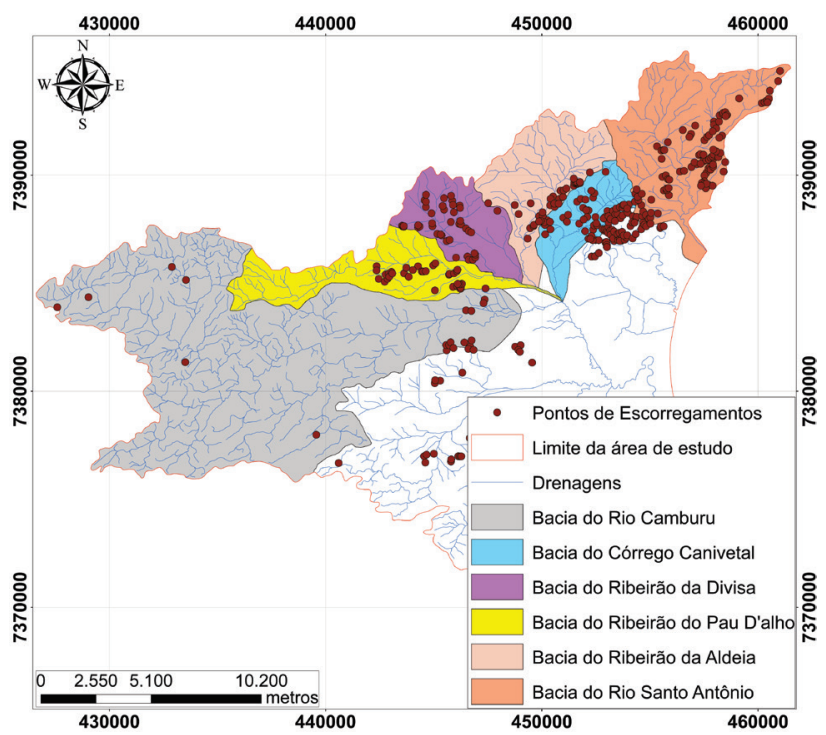

Figura 4. Figura de localização das bacias hidrográficas, onde foram aplicados os parâmetros morfométricos e também inseridos os pontos de cicatrizes de escorregamentos mapeados a partir das fotos aéreas da EMPLASA (2011).
V, VI, VII, X e XI. Essas unidades correspondem às unidades com maiores valores de declividade e amplitude altimétrica, e estão fortemente estruturadas e sob influência das estruturas geológicas, como os lineamentos e as Falhas de Camburu e Bertioga-Caraguatatuba. Essas bacias foram afetadas por escorregamentos do evento de Caraguatatuba em 1967, que culminaram em corridas de massa de grandes proporções.

Para essas bacias, além dos parâmetros morfométricos, foram analisados alguns fatores naturais/intrínsecos do meio físico, propriedades e características geológicas, bem como uso e ocupação do solo.

Os Quadros 2 e 3 sintetizam a descrição dos parâmetros analisados para cada bacia hidrográfica, levando em consideração, além dos parâmetros morfométricos, características físicas da bacia hidrográfica, que foram levantadas durante as atividades de campo e fotoleitura e fotointerpretação realizadas preliminarmente pelas análises de fotografias aéreas com pares estereoscópicos. Alguns parâmetros, como indícios de movimentos de massa (depósito de blocos e barramentos naturais), não foram mapeados em escala que propicie a confecção de um mapa. Assim, priorizou-se a identificação e a caracterização desses depósitos e barramentos naturais nas bacias hidrográficas mostradas na Figura 4. Apenas as cicatrizes de escorregamentos foram mapeadas e especializadas em escala de detalhe.

O Quadro 4 mostra os valores primários necessários para o cálculo dos parâmetros morfométricos analisados para as seis bacias hidrográficas da área de estudo.

Para o Ic, predominaram valores baixos, indicando um formato mais alongado das bacias hidrográficas. Os maiores valores de Ic correspondem a algumas bacias que apresentam registros de corridas de massa de maiores magnitudes (Canivetal e Divisa), cujos valores de Ic são maiores que 0,50. Trata-se de um indicador muito discutível, uma vez que, por exemplo, Augusto Filho (1993) considera que bacias mais arredondadas apresentam maiores chances de ocorrência de corridas de massa, e Crozier (1986) considera que bacias mais alongadas são mais suscetíveis e propensas à ocorrência desses processos.

A Dd corresponde à disponibilidade de energia para transporte sedimentar dentro de uma bacia hidrográfica. Para bacias com altos valores de Dd, é esperado que ocorram corridas de massa com maiores magnitudes e intensidades. As bacias analisadas apresentam valores de Dd sempre acima de 2,30, excetuando a Bacia do Ribeirão da Divisa, que apresenta valor de Dd igual a 2,03 (menor valor observado).

$\mathrm{O} \mathrm{Ir}$, considerado proporcional à $\mathrm{Dd}$, apresenta quase que o mesmo comportamento se comparado com a Dd. As bacias com registros de corridas de massa apresentam altos valores de Ir — sempre acima de 2.000, sendo 3.121 para o Rio Camburu - , excetuando as bacias do Córrego Canivetal e do Ribeirão da Divisa, que apresentam valores abaixo de 2.000 (menores valores observados). 


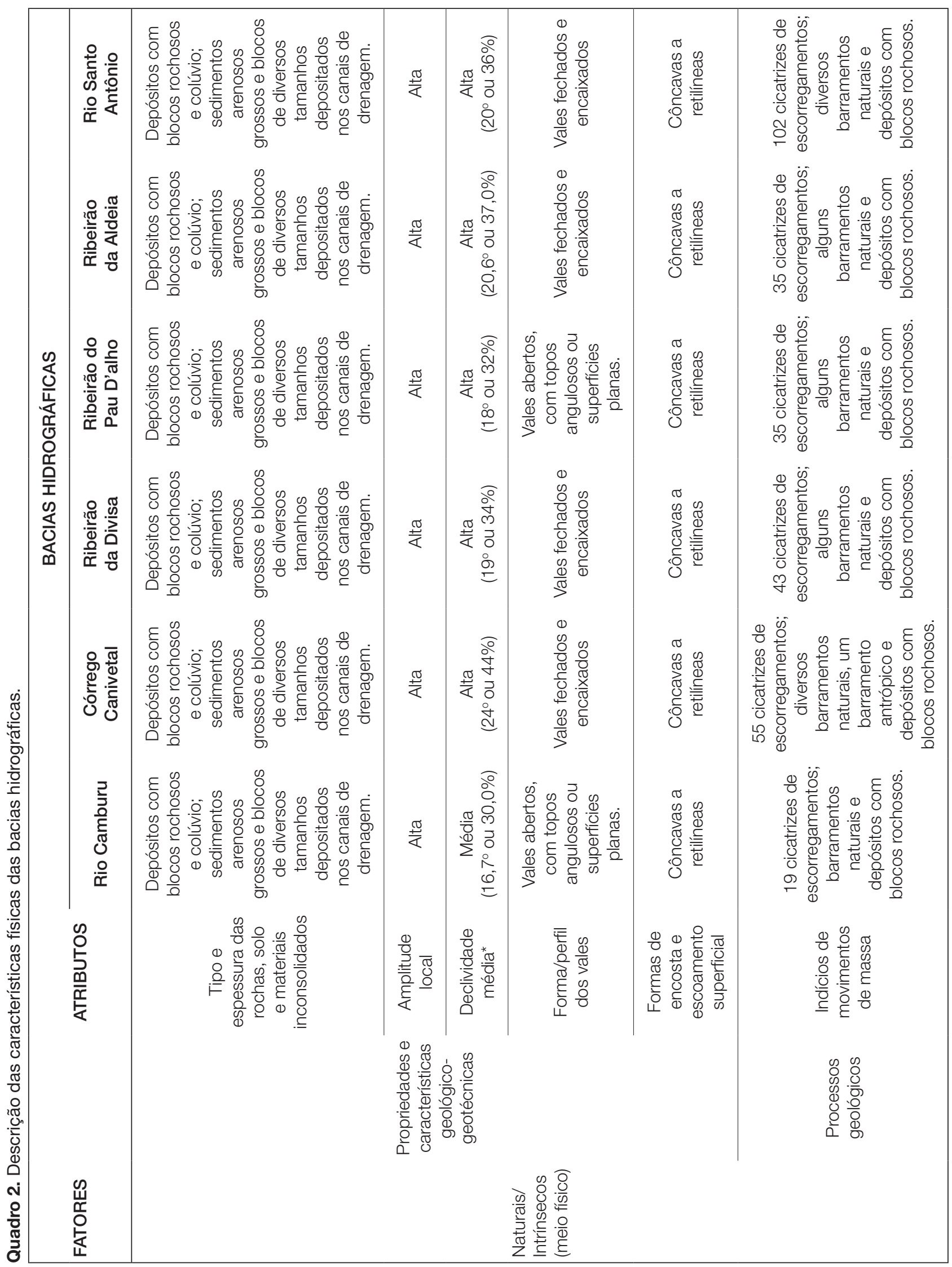




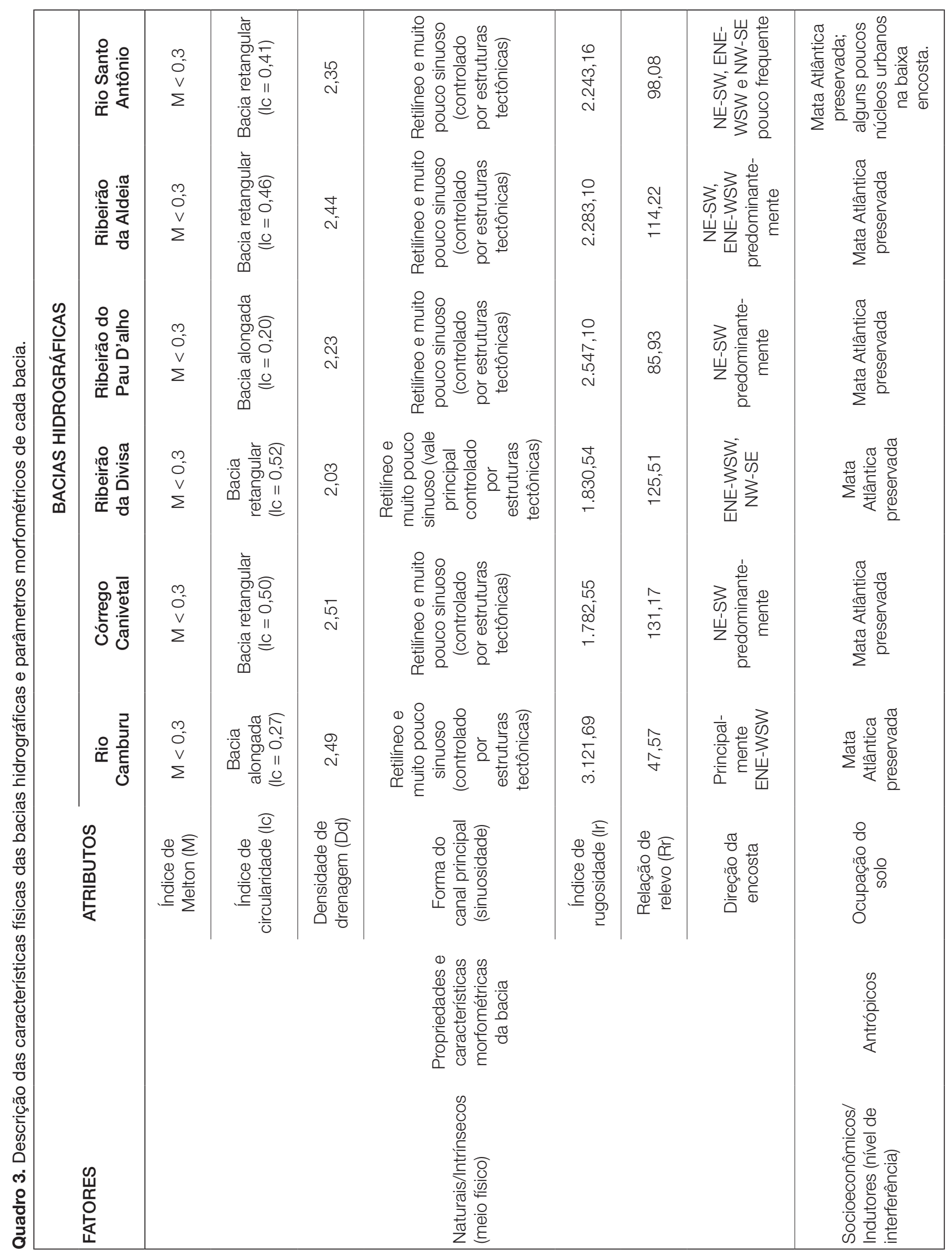


Os valores da $\mathrm{Rr}$ podem ser considerados altos, uma vez que variam entre 47 (Rio Camburu) e 131 (Córrego Canivetal). Essa relação expressa a capacidade da bacia em transportar e armazenar sedimentos. Dessa forma, as bacias que têm registros de corridas de massa apresentaram os maiores valores, como é o caso do Córrego Canivetal.

$\mathrm{O}$ M é utilizado para definir áreas suscetíveis a processos de corridas de massa, incluindo fluxos em geral (enxurradas, corridas de lama, terra ou detritos). Os valores de $\mathrm{M}$ foram todos abaixo de 0,3 , indicando que as bacias estudadas apresentam baixa suscetibilidade a processos de corridas. Esse parâmetro deve ser tratado com muito cuidado, visto que é historicamente conhecido que as bacias analisadas apresentam grande suscetibilidade à ocorrência de corridas.

A análise integrada entre os diversos parâmetros morfométricos das bacias hidrográficas mostra que, nas bacias conhecidas pela ocorrência de corridas de massa, há a presença de, pelo menos, dois parâmetros morfométricos com valores críticos, considerados muito favoráveis à ocorrência desses fenômenos. Como exemplo, pode-se citar a Bacia do Córrego Canivetal, que apresenta valor elevado de Dd e Rr; a Bacia do Rio Santo Antônio, apresentando valores elevados de Ir, Dd e Rr; e a Bacia do Ribeirão da Aldeia, que apresenta elevado valor de Ir e Rr. Vale ressaltar que essas bacias estão inseridas dentro da unidade fisiográfica II (domínio da Serra do Mar), apresentando altos valores de declividade e amplitude altimétrica, estando intimamente estruturadas segundo os lineamentos estruturais e as falhas da região.

Portanto, as bacias analisadas apresentam alta suscetibilidade à ocorrência de escorregamentos tanto por estarem inseridas dentro de um contexto geomorfológico (escarpas da Serra do Mar) e uma morfologia favorável à sua ocorrência quanto por apresentarem pelo menos dois parâmetros morfométricos considerados favoráveis para a ocorrência desses processos. As bacias apresentam também alto controle tectonoestrutural, verificado pelo controle das drenagens por fraturas, deixando estas com um padrão predominante retilíneo e com vales muito encaixados. Cicatrizes de escorregamentos nas encostas e depósitos associados a corridas de massa são facilmente encontrados tanto dentro do baixo/médio curso das drenagens (depósitos de blocos, por vezes apresentando imbricamento e inversão granulométrica) quanto na região da planície (depósitos arenosos/ argilosos com restos vegetais), indicando a ocorrência de processos de corridas de massa.

Com base nas análises dos escorregamentos, observou-se que encostas com direção e direção de inclinação paralelas ou subparalelas às estruturas geológicas (NE-SW e ENE-WSW, principalmente), tornam muito suscetível a ocorrência de escorregamentos (e.g., Cerri et al., 2017). Isso, com a potencialidade de ocorrência de corridas de massa, deve ser considerado, uma vez que escorregamentos são importantes fontes de materiais para as corridas de massa de origem primária e, quando somados aos sedimentos e materiais depositados nos canais de drenagem, são fontes para as corridas de massa de origem secundária.

As bacias hidrográficas com maiores registros históricos de corridas de massa (Canivetal, Camburu, Pau D'alho e Santo Antônio) apresentam direções das encostas predominantemente NE-SW e ENE-WSW, demonstrando,

Quadro 4. Valores primários e parâmetros morfométricos calculados para as bacias hidrográficas mais afetadas durante os eventos de escorregamentos e corridas em 1967.

\begin{tabular}{|c|c|c|c|c|c|c|}
\hline \multirow[b]{2}{*}{ Valores primários } & \multicolumn{6}{|c|}{ Bacias Hidrográficas } \\
\hline & $\begin{array}{c}\text { Rio } \\
\text { Camburu }\end{array}$ & $\begin{array}{l}\text { Córrego } \\
\text { Canivetal }\end{array}$ & $\begin{array}{l}\text { Ribeirão } \\
\text { da Divisa }\end{array}$ & $\begin{array}{c}\text { Ribeirão } \\
\text { do Pau } \\
\text { D'alho }\end{array}$ & $\begin{array}{l}\text { Ribeirão } \\
\text { da Aldeia }\end{array}$ & $\begin{array}{c}\text { Rio Santo } \\
\text { Antônio }\end{array}$ \\
\hline Área da bacia - A $\left(\mathrm{km}^{2}\right)$ & 128,60 & 12,70 & 16,80 & 23,50 & 22,70 & 37,50 \\
\hline Perímetro da bacia - Ac (km) & 78,00 & 17,90 & 20,20 & 38,00 & 25,00 & 34,00 \\
\hline Amplitude altimétrica - H (m) & $1.255,00$ & 709,00 & 900,00 & $1.141,00$ & 936,00 & 956,00 \\
\hline Amplitude topográfica máxima - Hm (m) & $1.275,00$ & 728,00 & 920,00 & $1.160,00$ & 948,00 & 965,00 \\
\hline Comprimento dos canais - Lt (km) & 319,88 & 31,93 & 34,17 & 52,46 & 55,37 & 87,99 \\
\hline Comprimento da bacia - Lh (km) & 26,80 & 5,55 & 7,33 & 13,50 & 8,30 & 13,00 \\
\hline \multirow[b]{2}{*}{ Parâmetros morfométricos } & \multicolumn{6}{|c|}{ Bacias Hidrográficas } \\
\hline & $\begin{array}{c}\text { Rio } \\
\text { Camburu }\end{array}$ & $\begin{array}{l}\text { Córrego } \\
\text { Canivetal }\end{array}$ & $\begin{array}{l}\text { Ribeirão } \\
\text { da Divisa }\end{array}$ & $\begin{array}{c}\text { Ribeirão } \\
\text { do Pau } \\
\text { D'alho }\end{array}$ & $\begin{array}{l}\text { Ribeirão } \\
\text { da Aldeia }\end{array}$ & $\begin{array}{c}\text { Rio Santo } \\
\text { Antônio }\end{array}$ \\
\hline Índice de circularidade (Ic) & 0,27 & 0,50 & 0,52 & 0,20 & 0,46 & 0,41 \\
\hline Índice de rugosidade (Ir) & $3.121,69$ & $1.782,55$ & $1.830,54$ & $2.547,10$ & $2.283,10$ & $2.243,16$ \\
\hline Índice de Melton (M) & 0,11 & 0,20 & 0,22 & 0,24 & 0,20 & 0,16 \\
\hline Densidade de drenagem (Dd) & 2,49 & 2,51 & 2,03 & 2,23 & 2,44 & 2,35 \\
\hline Relação do relevo (Rr) & 47,57 & 131,17 & 125,51 & 85,93 & 114,22 & 98,08 \\
\hline
\end{tabular}


assim, direções paralelas e/ou subparalelas às das foliações. As bacias do Ribeirão da Divisa e da Aldeia também apresentam encostas com tais direções, porém com predominância de encostas com direção NW-SE.

Portanto, bacias hidrográficas que apresentam maiores suscetibilidades à ocorrência de escorregamentos podem ser classificadas também como de alta potencialidade para corridas de massa. Assim, bacias que apresentam encostas com direção NE-SW/ENE-WSW, concordando com estruturas geológicas, apresentam maior possibilidade de fornecimento de sedimentos - vindos de escorregamentos para ocorrência de corridas.

Um bom exemplo dessa correlação entre corridas e direção das encostas da bacia pode ser observado no trabalho de Nery (2016), que, estudando a dinâmica das corridas de massa no Litoral Norte (Caraguatatuba, São Paulo), na Bacia Hidrográfica do Rio Santo Antônio, identifica quatro sub-bacias com alto índice de geração de corridas de grandes proporções e volumes. Essas sub-bacias têm direção NE-SW, apresentando potencial para geração de corridas com volumes totais acima de $100.000 \mathrm{~m}^{3}$. Gomes et al. (2015), estudando as bacias hidrográficas de Caraguatatuba, classificaram as bacias do Rio Camburu, Córrego Canivetal, Ribeirão da Divisa, Ribeirão do Pau D'alho e Ribeirão da Aldeia com as maiores magnitudes quanto à ocorrência de corridas de detritos. Essas bacias apresentam direções das encostas predominantemente NE-SW e ENE-WSW, concordando com as direções observadas para as foliações da região. Outro bom exemplo são as bacias hidrográficas estudadas, em trechos serranos, ao longo do Oleoduto Santos São Sebastião (OSBAT) por Gramani et al. (2005), com o intuito de analisar a potencialidade de geração de corridas de massa. Segundo esses autores, bacias com menores ordens de criticidade - e, consequentemente, com maior potencial de geração de corridas - na região de São Sebastião correspondem a bacias de direções que variam desde E-W até NNE-SSW, paralelas ou subparalelas às direções de foliações da região, alongadas e com forte estruturação, com vales encaixados e retilíneos.

Considerando-se que os escorregamentos são importantes fontes de sedimentos para as corridas, bacias mais alongadas (menores valores de Ic) e com direção das encostas paralela ou subparalela a estruturas geológicas (foliações, bandamentos etc. - direção NE-SW) tornam-se mais suscetíveis a processos de corridas. Isso se dá devido à maior quantidade de área suscetível a escorregamentos cuja direção de inclinação se torna paralela ou subparalela à direção das estruturas geológicas (Figura 5). À medida que a bacia de direção NE-SW vai aumentando seu arredondamento, menor será a área de encostas com direção concordante às estruturas geológicas, diminuindo, assim, a suscetibilidade a escorregamentos. Dessa maneira, a área propícia à ocorrência de escorregamentos em bacias mais alongadas NE-SW é maior do que em bacias arredondadas, fazendo com que haja maior disponibilidade de sedimentos para os eventos de corridas de massa.

Kanji et al. (2003), mostrando fatores geológicos que influenciam a ocorrência de corridas de massa, descrevem que não existem grandes afirmações que relacionam quais os tipos litológicos mais propícios à ocorrência desses eventos, exceto em terrenos que são constituídos por depósitos piroclásticos. Esses autores destacam, principalmente, dois fatores geológicos como sendo de grande importância:

1. disponibilidade de materiais friáveis e pouco consolidados (soltos) ou um manto de alteração residual (composto por terra, seixos e grandes blocos). Esse material deve ser capaz de ser removido e transportado para contribuir com a formação das corridas de massa;

2. condições geológicas propícias e capazes de formar encostas íngremes.

Os dois fatores supradescritos são facilmente encontrados na área de estudo (Serra do Mar, na região de Caraguatatuba e São Sebastião). Os solos residuais gnáissicos, colúvios e depósitos de tálus, são frequentemente encontrados, preservando estruturas geológicas e contendo seixos, blocos e matacões de diversos tamanhos.

Em relação à condição de formação de encostas íngremes, as bacias estudadas apresentam alta declividade associada, tanto nas regiões a montante das bacias hidrográficas quanto nas encostas que acompanham os cursos das drenagens, em especial aquelas localizadas na unidade

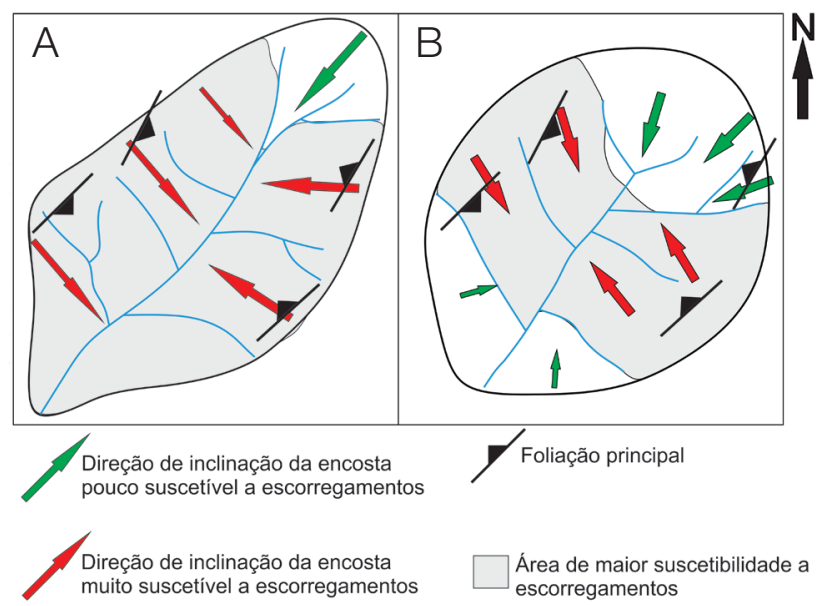

Figura 5. Circularidade da bacia e suscetibilidade à ocorrência de corridas de massa considerando os materiais de escorregamentos provenientes das encostas laterais como fonte principal. Quanto maior a circularidade da bacia, menor é a área das encostas que apresentam mesma direção que as foliações, sendo menor a contribuição dos escorregamentos como fonte de materiais para a corrida. 
fisiográfica II. Destaca-se que a evolução das principais bacias hidrográficas da região da Serra do Mar, no litoral norte do Estado de São Paulo, está muito condicionada às estruturas geológicas, influenciadas pelas Falhas do Camburu e Bertioga-Caraguatatuba.

Como há alta estruturação NE-SW no embasamento da Serra do Mar, as bacias estudadas, em sua quase totalidade, apresentam-se alongadas segundo essa direção (NE-SW a ENE-WSW). Desse modo, não se pode desconsiderar o fator estrutural no controle geomorfológico e, consequentemente, no controle da ocorrência de escorregamentos, sendo que estes alimentam de sedimentos e detritos as corridas de massa, especialmente a partir da ocorrência de um escorregamento de grande porte ou em eventos de escorregamentos generalizados.

Dessa forma, vale considerar as estruturas geológicas, condicionantes dos escorregamentos, para análises quanto à suscetibilidade à ocorrência de eventos de corridas de massa. Portanto, trata-se de um processo associado à dinâmica dos escorregamentos em encostas como das condições morfométricas e hidrológicas da bacia hidrográfica.

\section{CONCLUSÕES}

A compartimentação fisiográfica, com a análise dos parâmetros morfométricos, possibilitou a avaliação integrada de diferentes atributos do meio físico em relação à suscetibilidade de bacias hidrográficas à ocorrência de corridas de massa, demonstrando que o controle estrutural na evolução geomorfológica dessas bacias é um fator fundamental tanto na distribuição de encostas com direções favoráveis à ocorrência de escorregamentos como nos resultados dos parâmetros morfométricos dessas bacias.

Segundo a compartimentação fisiográfica realizada, bacias hidrográficas localizadas em porções escarpadas, com alta declividade, forte estruturação das drenagens por estruturas geológicas e vales encaixados (unidade fisiográfica II, por exemplo), apresentam valores maiores para os parâmetros morfométricos, indicando maior potencialidade de ocorrência desse processo.

Considerando os escorregamentos como principal fonte de sedimentos para as corridas de massa, as bacias com direção NE-SW, com valores de Ic menores que 0,50 , indicando bacias hidrográficas mais alongadas, tornam-se mais suscetíveis a esses processos. Isso ocorre devido à maior quantidade de encostas propensas à ocorrência de escorregamentos.

Dessa forma, a análise conjunta entre a compartimentação fisiográfica com identificação de feições-chave do relevo (declividade, amplitude, estruturação geológica influenciando o relevo etc.) e os parâmetros morfométricos possui uma relevância fundamental na identificação de bacias hidrográficas suscetíveis a corridas de massa.

\section{AGRADECIMENTOS}

Ao Conselho Nacional de Desenvolvimento Científico e Tecnológico (CNPq) pelo apoio financeiro que possibilitou a realização deste trabalho e ao Laboratório de Geologia de Engenharia e Ambiente (GEMA) da Universidade Estadual Paulista Campus Rio Claro pelo apoio e suporte técnico.

\section{REFERÊNCIAS}

Augusto Filho, O. (1993). O estudo das corridas de massa em regiões serranas tropicais: um exemplo de aplicação no município de Ubatuba, SP. VII Congresso Brasileiro de Geologia de Engenharia, 63-71. Rio de Janeiro: ABGE.

Campanha, G. A., Ens, H. H., Ponçano, E. W. (1994). Análise morfotectônica do Planalto de Juqueriquerê, São Sebastião (SP). Brazilian Journal of Geology, 32-42.

Cerri, L. E., Almeida, J. G. (1990). Instabilidade da Serra do Mar no Estado de São Paulo: situações de risco. I Simpósio Latino-Americano sobre Risco Geológico Urbano, 342-351. São Paulo: ABGE São Paulo.

Cerri, R. I., Reis, F. A., Gramani, M. F., Giordano, L. C., Zaine, J. E. (2017). Landslides Zonation Hazard: relation between geological structures and landslides occurrence in hilly tropical regions of Brazil. Anais da Academia Brasileira de Ciências.

Chen, C. Y., Yu, F. C. (2011). Morphometric analysis of debris flow and their source areas using GIS. Geomorphology, 387-397.

Chieregati, L. A., Theodorovicz, A. M., Theodorovicz, A., Menezes, R. G., Chiodi Filho, C., Ramalho, R. (1982). Projeto Folhas Natividade da Serra e Caraguatatuba. Projeto Folhas Natividade da Serra e Caraguatatuba: Relatório Final. Brasília: CPRM.

Christofoletti, A. (1980). Geomorfologia. São Paulo: Blücher.

Crozier, M. J. (1986). Landslides: causes, consequences \& environment. London: Taylor \& Francis.

Cruz, O. (1975a). A serra do mar e o litoral na área de Caraguatatuba-SP: contribuição à geomorfologia litorânea tropical. Revista Brasileira de Geografia, 37, 99-151.

Cruz, O. (1975b). Evolução das vertentes nas escarpas da serra do Mar em Caraguatatuba-SP. Anais da Academia Brasileira de Ciências, 47. 
De Scally, F., Slaymaker, O., Owens, I. (2001). Morphometric Controls and Basin Response in the Cascade Mountains. Geografiska Annaler, 117-130.

Dias, V. C., Vieira, B. C., Gramani, M. F. (2016). Parâmetros morfológicos e morfométricos como indicadores da magnitude das corridas de detritos na Serra do Mar Paulista. Confins.

DNPM/CPRM - Departamento Nacional de Produção Mineral/Serviço Geológico do Brasil. (1991). Mapa Geológico da Folha Pico do Papagaio 1:50.000. Projeto de Integração Geológica da Região Metropolitana de São Paulo. Brasília: CPRM.

EMPLASA-Empresa Paulista de Planejamento Metropolitano. (2011). Mapa geológico em escala 1:50.000 das folhas Caraguatatuba e Pico do Papagaio e São Sebastião. São Paulo: EMPLASA.

Fúlfaro, V. J., Ponçano, W. L., Bistrichi, C. A., Stein, D. P. (1976). Escorregamentos de Caraguatatuba: expressão atual, e registro na coluna sedimentar da planície costeira adjacente. Congresso Brasileiro de Geologia de Engenharia, 2, 341-350. Rio de Janeiro: ABGE.

Gomes, C. L. R., Ogura, A. T., Gramani, M. F., Corsi, A. C., Alameddine, N. (2008). Retro-análise da corrida de massa ocorrida no ano de 1967 nas encostas da Serra do Mar, vale dos rios Camburu, Pau D'Alho e Canivetal, município de Caraguatatuba - SP: quantificação volumétrica dos sedimentos depositados nas planícies de inundação. XII Congresso Brasileiro de Geologia de Engenharia e Ambiental, CD-ROM. Recife: ABGE.

Gomes, M. C., Dias, V. C., Vieira, B. C. (2015). Influência dos Parâmetros Morfométricos na Magnitude de Corridas de Detritos em Caraguatatuba/SP, Serra do Mar: Análise Preliminar. XV Congresso Brasileiro de Geologia de Engenharia e Ambiental, p. 6. Bento Gonçalvez: ABGE.

Gramani, M. F. (2001). Caracterização geológica-geotécnica das corridas de detritos ("Debris Flows") no Brasil e comparação com alguns casos internacionais. Dissertação (Mestrado). São Paulo: Escola Politécnica - USP.

Gramani, M. F. (2013). As corridas de detritos (debris flow) no Ribeirão Cágado, Serra do Mar, Município de Cubatão, SP. VI Conferência Brasileira de Encostas. Angra dos Reis: ABMS.

Gramani, M. F., Olivito, J. P., Augusto Filho, O., Magalhães, F. S. (2005). Análise da potencialidade de geração de corridas de massa nos trechos serrados do duto OSBAT.
XI Congresso Brasileiro de Geologia de Engenharia e Ambiental. Florianópolis: ABGE.

Hasui, Y., Carneiro, C. D., Almeida, F. F., Bartorelli, A. (2012). Geologia do Brasil. São Paulo: Oficina de Textos.

Heilbron, M., Pedrosa-Soares, A. C., Campos Neto, M. C., Silva, L. C., Trouw, R. A., Janasi, V. A. (2004). Província Mantiqueira. In: V. Mantesso-Neto, A. Bartorelli, C. D. Carneiro, B. B. Brito-Neves (Eds.), Geologia do continente sul-americano: evolução da obra de Fernando Flávio Marques de Almeida (203-235). São Paulo: Beca.

Horton, R. E. (1945). Erosional development of streams and their drainage basins: hydrophysical approach to quantitative morphology. Geological Society of America Bulletin, 275-370.

IBGE - Instituto Brasileiro de Geografia e Estatística. (2016). Banco de dados: cidades. Disponível em: <https:// cidades.ibge.gov.br/brasil/sp/caraguatatuba/panorama $>$. Acesso em: 10 jan. 2017.

Infanti Jr., N., Fornasari Filho, N. (1998). Processos de dinâmica superficial. In: A. M. S. Oliveira, S. N. A. Brito (Eds.), Geologia de Engenharia (9, 131-152). São Paulo: ABGE.

IPT - Instituto de Pesquisas Tecnológicas. (1978). Geologia da região administrativa 3 (Vale do Paraíba) e parte da Região Administrativa 2 (Litoral) do estado de São Paulo: mapa geológico em escala 1: 200.000. Instituto de Pesquisas Tecnológicas, 1106.

IPT - Instituto de Pesquisas Tecnológicas. (1987). Estudos das instabilizações da Serra do Mar na Região de Cubatão, objetivando a caracterização do fenômeno "corrida de lama" e a prevenção de seus efeitos. Relatório IPT, 25065.

IPT - Instituto de Pesquisas Tecnológicas. (1988). Estudos da instabilização de encostas da Serra do Mar na Região de Cubatão, objetivando a caracterização do fenômeno "corrida de lama" e a prevenção de seus efeitos. Relatório IPT, 25258.

IPT - Instituto de Pesquisas Tecnológicas. (1991). Desenvolvimento de um plano de estudos para análise, prevenção e contenção do fenômeno da corrida de massa na Região de Cubatão, em colaboração com o Governo Japonês. Relatório IPT, 29123.

IPT - Instituto de Pesquisas Tecnológicas. (2006). Análise do risco de processos de movimentos de massa e estudos de determinação de cota máxima de inundação para subsidiar a escolha entre as três alternativas locacionais 3A, 4A e 4B da Unidade de Tratamento de Gás do Gasoduto Mexilhão, Caraguatatuba, SP. Relatório Técnico, 90643-205. 
Iverson, R. M., Reid, M. R., LaHusen, R. G. (1997). Debrisflow mobilization from landslides. Annual Review of Earth and Planetary Sciences, 85-138.

Jakob, M. (1996). Morphometric and geotechnical controls of debris flow frequency and magnitude in southwestern British Columbia. Tese (Doutorado). Vancouver: Universidade da Colúmbia Britânica.

Kanji, M. A., Massad, F., Cruz, P. T. (2003). Debris Flow in Areas of Residual Soils: Occurrence and Characteristics. International Workshop on Occurrence and Mechanism of Flows in Natural Slopes and Earthfills, 1-13.

Melton, M. A. (1954). An analysis of the relation among elements of climate, surface properties and geomorphology. Nova York: Universidade Colúmbia.

Nakazawa, V. A., Cerri, L. E. (1990). Os escorregamentos ocorridos em Petrópolis - RJ em fevereiro de 1988: ações emergenciais. I Simpósio Latino-Americano sobre Risco Geológico Urbano, 325-333. São Paulo: ABGE.

Nery, T. D. (2016). Dinâmica de corridas de detritos no Litoral Norte de São Paulo. Tese (Doutorado). São Paulo: FFLCH-USP.

Ogura, A. T., Augusto Filho, O. (1991). The Morin DebrisFlow Disaster at Petropolis City, Rio de Janeiro State, Brazil. Landslides News, 22-25.

Ponçano, W. L. (1981). Mapa Geomorfológico do Estado de São Paulo. São Paulo: Instituto de Pesquisas Tecnológicas do Estado de São Paulo, Divisão de Minas e Geologia Aplicada.

Ross, J. L., Moroz, I. C. (1997). Mapa Geomorfológico do Estado de São Paulo. Departamento de Geografia (FFLCH - USP). Laboratório de Cartografia Geotécnica - Geologia Aplicada - IPT/FAPESP. São Paulo: USP.
Schumm, S. A. (1956). Evolution of drainage systems and slopes in badlands at Perth Amboy, New Jersey. Geological Society of America Bulletin, 597-646.

Silva, R. F. (2013). Análise de magnitude e frequência espacial de movimentos de massa em Caraguatatuba-SP. Tese (Doutorado). São Paulo: FFLCH - USP.

Takahashi, T. (1981). Debris Flow. Annual Review of Fluid Mechanics, 57-77.

Vedovello, R., Mattos, J. T. (1998). A utilização de Unidades Básicas de Compartimentação (UBCs) como base para a definição de Unidades Geotécnicas: uma abordagem a partir do Sensoriamento Remoto. III Simpósio Brasileiro de Cartografia Geotécnica. Florianópolis: UFSC/ABGE.

Vieira, B. C., Gramani, M. F. (2015). Serra do Mar: The Most "Tormented" Relief in Brazil. In: B. C. Vieira, A. A. Salgado, L. J. Santos (Eds.), Landscapes and Landforms of Brazil (285-297). Dordrecht, Netherlands: Springer.

Wilford, D. J., Sakals, M. R., Innes, J. L., Sidle, R. C., Bergerud, W. A. (2004). Recognition of debris flow, debris flood and flood hazard through watershed morphometrics. Landslides, 61-66.

Zaine, J. E. (2000). Mapeamento geológico-geotécnico por meio do método do detalhamento progressivo: ensaio de aplicação na área urbana do município de Rio Claro (SP). Tese (Doutorado). Rio Claro: Instituto de Geociências e Ciências Exatas - UNESP.

Zaine, J. E. (2011). Método de fotogeologia aplicado a estudos geológico-geotécnicos: ensaio em Poços de Caldas, $M G$. Tese (Livre Docência). Rio Claro: Instituto de Geociências e Ciências Exatas - UNESP. 